John Carroll University

Carroll Collected

2019

\title{
Analytical framework for evaluating digital diplomacy using network analysis and topic modeling: Comparing South Korea and Japan
}

Sejung Park

John Carroll University, sjpark@jcu.edu

Dahoon Chung

Sogang University

Han Woo Park

YeungNam University

Follow this and additional works at: https://collected.jcu.edu/fac_bib_2019

Part of the Social Media Commons

\section{Recommended Citation}

Park, Sejung; Chung, Dahoon; and Park, Han Woo, "Analytical framework for evaluating digital diplomacy using network analysis and topic modeling: Comparing South Korea and Japan" (2019). 2019 Faculty Bibliography. 59.

https://collected.jcu.edu/fac_bib_2019/59 


\title{
Analytical framework for evaluating digital diplomacy using network analysis and topic modeling: Comparing South Korea and Japan
}

\author{
Sejung Park, Dahoon Chung, Han Woo Park
}

\begin{abstract}
A B S T R A C T
Keywords: Digital diplomacy

Soft power

Social media

South Korea

Japan

This study introduces a data-driven approach for assessing the practices and effectiveness of digital diplomacy, using the cases of South Korea and Japan. The study compared the networking power of public diplomacy organizations based on social media use, engagement with the public, interaction patterns among the public, and public perceptions and attitudes toward organizations. This was accomplished through a three-step method employing social network analysis and topic modeling. The network analysis found that the Korean public diplomacy organization generated a larger, more loosely connected, and decentralized comment network than the Japanese organization, which presented a "small-world" connectivity pattern with highly interconnected actors. The findings also suggest that, compared to the Japanese organization, the Korean organization was successful in not only enhancing its soft power through social media but also building international networks among the foreign public.
\end{abstract}

\section{Introduction}

Social media has become important for providing government information and for managing stakeholder relationships. Diplomats have utilized social media as a new toolkit for engaging with both state and non-state actors. The wide application of social media to the field of diplomacy has to do with a paradigm shift in public diplomacy (hereafter, "PD") from propaganda to a "relational, networked, and collaborated" approach, referred to as "new PD" (Melissen, 2005; Park \& Lim, 2014; Zaharna, Arsenault, \& Fisher, 2013).

As communication technology facilitates information access and the exchange of political values between countries, the role of non-state actors, including the domestic and foreign public, has been enhanced in the course of implementing diplomacy (Barnett, Ruiz, Xu, Park, \& Park, 2017; Barnett, Xu et al., 2017, Kim, 2018). Thus, in the era of digital diplomacy, the achievement of a state's foreign policy goals has moved beyond its direct control. As such, how to attract diverse stakeholders and enable them to react to a state's policy goals through persuasion has become an important consideration (Nye, 2008). Accordingly, scholars and pundits have turned their attention to attitudinal and cognitive goals, as well as engagement with non-stakeholders (Fitzpatrick, 2013). While social media is an efficient instrument for realizing this new trend in $\mathrm{PD}$, the results depend on how smartly diplomats utilize this tool 
to attract public interest and build meaningful relationships with the public (Park \& Lim, 2014).

In this context, a question arises as to how diplomats can harness the full potential of social media. Despite the growing academic and pragmatic interest in digital diplomacy and its potential to empower a government's capability to engage with the public, research on governments' use of social media and digital diplomacy practices is in its infancy (Criado et al., 2013). Existing studies have focused on governments' communication strategies and how they adopt social media to reach out to the public (Strauß, Kruikemeier, van der Meulen, \& van Noort, 2015). However, the literature has paid insufficient attention to the public side. Consequently, we know little about the results of governments' use of social media. This is a significant problem since considering what recipients think about governments' activities, policies, and foreign affairs is key to evaluating the effectiveness of PD (Gullion, 1965).

Another research problem in this field is that most studies are dominated by American and European contexts (Melissen \& Keulenaar, 2017). Outside of Western contexts, analyses of East Asian countries can offer non-Western insights and perspectives into the current debate on digital diplomacy (Ayhan, 2018).

To fill such gaps, this study introduces an analytical framework for assessing the practices and effectiveness of digital diplomacy by linking international relations literature, asocial network approach, and topic modeling. The international relations literature highlights the need to gauge the networking power of diplomacy agents to engage with various stakeholders and the importance of mining public perceptions and attitudes regarding a foreign country. These are systemically measured by employing two big data analytics: a social network analysis and topic modeling algorithm using latent Dirichlet allocation (LDA).

First, the social network analysis revealed the structural characteristics of diplomacy organizations' comment networks, the extent of their outreach to and engagement with the public, and the interaction patterns among the publics embedded in Facebook networks. Second, top influencers (authorities, hubs, and brokers) who leverage information propagation and framing were identified in each organization's comment network in terms of centrality measures. We also explored how PD organizations manage relationships with their top influencers. Third, computer-assisted text analyses of large-scale public comments left on PD organizations' posts detected public opinion and sentiment.

Thus far, the effectiveness of diplomatic campaigns has largely depended on traditional methods, including public polls (Lee, 2008). However, survey results do not always reflect the hearts and voices of individuals. This is because polls only rely on the "mouths" of respondents through questionnaires and responses by telephone. Digital trace data are based on individuals' actions, not words. For example, people may post their feelings and opinions about a country on social media. Such comments are not comparable to telephone survey responses where a hundred people may have answered carelessly. It is also important to note that on social media one's comments attract attention from others and may influence others' thoughts and perceptions when processing information (Chung, 2017). As such comments are repeated, people's attention on certain countries may naturally increase. Thus, comment data can reveal public interest in and perceptions of a foreign country and government services.

\section{Evaluation of digital diplomacy}

\subsection{Digital diplomacy}

Existing studies have focused on how and to what extent diplomats use social media. It has been found that despite the importance of employing social media in PD, pundits have struggled to realize the potential of social media (Melissen \& Keulenaar, 2017). Kuzma (2010) found that $70 \%$ of Asian governments used social media as a one-way communication channel to disseminate information. Thus, they are failing to utilize the participatory and interactive functions of social media. Similarly, Kavanaugh et al.'s (2011) study suggested that local government officials in Arlington, Virginia, and the National Capitol Region around Washington DC lack pragmatic skills and knowledge in social media management. Fisher (2010) contended that a mistake that PD practitioners often make is using social media as an information channel that does not necessarily facilitate multi-lateral networks.

However, the extent to which diplomats harness the full benefits of social media has been examined very little. The more serious problem is that they have neglected the aspect of communication and engagement between states and the foreign public (Manor, 2016). Considering that, beyond mere information dissemination, listening to what the public thinks and participating in two-way communication are key to maximizing the effects of PD in the long term (Fitzpatrick, 2013). Engaging with target audiences through social media is a way to overcome the limitations of traditional diplomacy, as it enhances mutual understanding and shared interests among countries and the public (Fitzpatrick, 2013).

\subsection{A network framework for digital diplomacy}

The development of Internet communication technologies has broadened the scope of actors that affect and are affected by diplomatic activities. In the past, diplomacy was primarily a government-to-government (G2G) relationship. Today, a government indirectly targets the public (G2P relationship), and even public-to-public (P2P) communication can constitute diplomatic actions. Rather than one-way relationships, these mutual interactions are emphasized, and communication has become diverse.

Previously, PD meant an "overseas information program" focusing on how to present information to the foreign public (Zaharna, 2005). The new visions of digital diplomacy embrace a network approach to achieve attitudinal and cognitive goals, build relationships, and facilitate dialogue among diverse stakeholders (Fitzpatrick, 2013). This approach emphasizes a decentralized mode of communication, as well as building and managing diverse connections (Park \& Lim, 2014). The potential benefit of activating 
connections is the possible contribution to collaboration in the foreign policy decision-making process. Furthermore, it has been noted that to maximize the effects of $\mathrm{PD}$, interacting with different communities and bridging the domestic and foreign public are important, as this helps inform and influence the foreign public (Fisher, 2010; Zaharna, 2005).

As the objective of digital diplomacy is utilizing a digital platform to enhance mutual understanding and communication between the governing and governed, rather than the one-way propagation of ideas and values, it is important to consider the aspects of communication and engagement between diplomatic staff and target audiences (Melissen \& Keulenaar, 2017). Therefore, it is important to develop a new evaluation standard to assess digital diplomacy that reflects the relationship between agents (government) and stakeholders (public).

Network analysis is useful for measuring the network capability of organizations and the relational dynamics in communication networks by revealing the structural characteristics of networks and the patterns of interaction among agents and publics (Xu, Park, Kim, \& Park, 2016; Xu, Park, \& Park, 2015). In the context of diplomacy, understanding network structures enables the measurement of communication flow; evaluation of the extent to which organizations generate ties with stakeholders; and identification of key agents who facilitate, bridge, or change the network (Park \& Lim, 2014). For example, a non-centralized network may indicate that communication occurs from different points of interaction, rather than from a single central point, and the network is relatively resistant to external disruption (Fisher, 2010). Identifying key engaging agents and groups as well as their roles in the network facilitates the planning and development of strategies for policy programs.

Recent PD literature applying social network analysis is limited to egocentric networks, and the units of analysis are usually the positions of individuals (Zaharna, 2013). However, this approach can hardly grasp the characteristics of the whole network, which are essential for evaluating the design and implementation of PD initiatives (Zaharna, 2013). Thus, this study maps the whole networks of PD organizations.

\subsection{Public diplomacy and soft power}

As a diplomatic method, PD is defined as "an instrument used by states, associations of states, and sub-state and non-state actors to understand cultures, attitude, and behavior; to build and manage relationships; and to influence thoughts and mobilize actions to advance their interests and values" (Gregory, 2011, p. 353).

During the Cold War, PD was used as a tool for powerful nations and others to accomplish their internal agendas in the international community (Leonard, 2002). Since then, and especially after the terrorist attacks of September 11, 2001, PD has been more broadly studied from the perspectives of mass communication, political affairs, and international relationships (Leonard, 2002). This approach significantly contributed to establishing an analytic framework for PD. Gilboa (2008a) further organized an analytic framework for PD by utilizing "time" as a comparative analysis framework. In this process, cultural diplomacy has been described as a sub-notion of PD and an extended tool for soft power (Gilboa, 2008b). As indicated in Table 1, Gilboa (2008a) proposed three types of PD: immediate, mid-term, and long-term diplomacy.

He categorizes cultural diplomacy as long-term PD. Thus, culture in PD implies that cultural diplomacy can be practiced as a type of PD. Cultural diplomacy aims to eventually expand "soft power." Power refers to an actor's ability to control others to do what he or she wants through social relations and to affect others' practices; soft power, meanwhile, is achieved through "attraction rather than coercion or payments" (Barnett \& Raymond, 2005; Nye, 2004, p. 256). Nye (2004) identified three main resources for soft power: the attractiveness of a country's culture, political values, and foreign policies. Lee (2009) further expanded Nye's soft power into five categories: (1) projecting attractive and secure images of a country, (2) producing other countries' support for foreign policies, (3) changing the perceptions and preferences of foreign publics, (4) maintaining the unity of community, and (5) increasing the domestic popularity of a leader or government. Leonard (2002) argue that cultural diplomacy is the best example of soft power-specifically, it represents the possibility of communicating values and ideas via the conduit of culture.

Thus far, the literature on public relations and PD has focused on conceptual and historical arguments in the establishment of PD and soft power constructs (Buhmann, 2016). However, their measurement and evaluation remain an open question. The issue here is that studies have rarely considered the "reception" of PD, although the effectiveness of PD depends on the perceptions of target audiences. It is important, therefore, to consider responses to the messages intended to produce the desired images and outcomes when evaluating the effectiveness of PD communication. Though it is difficult to identify cause-and-effect relationships between organizational goals and public perceptions, data on public perceptions can reveal the "values, norms, and stereotypes" of the public regarding a foreign country, organizational activities, or foreign affairs, which may prompt or hamper the desired outcomes (Pamment, 2014).

\section{Table 1}

Framework for analysis.

Source: Gilboa (2008).

\begin{tabular}{llll}
\hline Range & Immediate & Intermediate & Long \\
\hline Time & Hours/days & Weeks/months & Years \\
Purpose & Reactive & Proactive & Relationship \\
Media/public opinion & News management & Strategic communication & Building favorable Conditions \\
Government & Closely linked & Partially linked & Remotely linked \\
PD Instrument & Advocacy; International broadcasting; & International public relations; cooperate diplomacy & Cultural diplomacy; Exchanges; \\
& Cyber PD & Diaspora PD & Branding \\
\hline
\end{tabular}


The importance of perception and attitude has been documented in research on public relations and PD, suggesting a positive link between attitudes and behavioral outcomes relevant for PD (Lee, 2009; Yun, 2014). Shaping perceptions and attitudes about a country among foreign publics in a way that positively affects the country's image a nd reputation is a desired outcome in PD (Buhmann, 2016; Melissen, 2005). In this context, we propose that the concept of soft power can be used as an analytical framework to measure PD performance since PD aims to build and project a country's soft power (Buhmann, 2016; Melissen, 2005). Thus, we propose that, along with a PD agency's network capability, measuring public perceptions and attitudes through the lens of Nye's soft power concept is a useful proxy for evaluating PD performance using the following three indicators: the attractiveness of a country's culture, political values, and foreign policies.

\section{Public diplomacy and soft power in South Korea and Japan}

\subsection{South Korea}

In the 1970s, the primary purpose of Korean traditional diplomacy was maintaining the political system and ideologies and promoting economic growth. In 1988, the Korean government hosted the Olympic Games, and this event re-established diplomatic relationships with communist states. As Korean culture became popular in China with the "Korean Wave" during the 1990s, the government began to recognize the importance of soft power in promoting its culture (Jang \& Paik, 2012). Since 2010, given the country's global popularity and reputation, Korean PD has become more focused on strengthening cultural competitiveness (Jang \& Paik, 2012).

The challenges of Korean PD include redundancies and a lack of coordination in PD practices as well as the allocation of budgets among government agencies (Korea Focus, 2015; Sam, Song, \& Moore, 2012). Although the Ministry of Foreign Affairs (MOFA) and its affiliated organization the Korea Foundation (KF) are the leading entities for PD, the Ministry of Culture, Sports, and Tourism (MCST) is also a major organization that performs cultural diplomacy (Cho, 2012; MOFA, 2016). As such, MCST is more active than MOFA in terms of undertaking major cultural diplomacy tasks (Kim, 2011).

To overcome such challenges and create an integrated PD framework, Korea passed the "Public Diplomacy Act" in 2016 with the goal of improving "Korea's image and prestige" in the world by establishing foundations and increasing PD efficiency (MOFA, 2016). The act established a PD committee, which produced Korea's first basic PD plan for 2017-2021, a comprehensive action plan for conducting and coordinating PD-related activities. Under the control of MOFA, the committee consists of national and local governments, including MCST, as well as people from academia and the private sector. KF was designated as the PD overseer. Table 2 summarizes the major tasks and functions of Korean PD organizations.

Given that global audiences may encounter many facets of Korean culture, including K-pop, K-beauty, and K-drama, on the Internet (Kim, Heo, Choi, \& Park, 2014; Meza \& Park, 2015; Xu et al., 2017), MOFA took action to promote Korean culture through digital PD. The Ministry appointed 500 students as cyber diplomats and formed an official agreement with the Voluntary Agency Network of Korea (VANK), the country's largest private organization (Ayhan, 2018).

Han Hyejin, a spokesperson at MOFA, commented on the purpose of the agreement. Specifically, it aims to jointly nurture civilian digital diplomats and facilitate the spread of digital hallyu (the rising awareness of Korean popular culture) to increase people's understanding of Korean diplomacy through public-private partnerships in the field of digital networks.

\subsection{Japan}

In the 1950s and 1960s, the objective of PD in Japan was to promote an image of transition from a formerly militaristic state to a new, peace-loving, and democratic country (Cho, 2012). Japan also used PD in the 1970s and 1980s to embrace anti-Japanese sentiment among other Asian countries against its economic advancement (Jung \& Yoon, 2009). In this way, Japan worked for a long time, via PD, to build an image of a faithful and reliable partner in the international community (Jung \& Yoon, 2009). Suffering from the crash of the bubble economy in the 1990s, following the culmination of the high economic growth period of the 1980s, Japan's economy plunged into a deep recession.

As South Korea and China emerged to rival Japan, which had expanded during the 2000s in terms of technology and the manufacturing industry, Japan began to pay attention to culture as a new industrial power. As such, since 2000, the recent goals of PD have focused on the soft power industry and cultural diplomacy (Michal, 2009). This transition was accompanied by the term "Cool Japan" (McGray, 2009). Japanese animation, for example, became popular because it incorporated foreign culture into animation without resistance (McGray, 2009). In this way, Japan created animation that people around the world could enjoy instead of catering to domestic demand by reflecting traditional Japanese values or aesthetics.

Today, PD in Japan is characterized by government-driven aspects and is categorized into international press releases and international cultural interchanges (Nakamura, 2013). The goal of Japanese PD is to communicate information about Japanese foreign policy and introduce Japanese culture to increase the understanding of Japan throughout the world (MOFA, 2018; Farina, 2018).

Table 3 lists the core PD organizations in Japan, along with their major tasks and functions.

Among these, the Agency of Cultural Affairs, established in 1968, came under the purview of the Ministry of Education, Culture, Sports, Science and Technology (MEXT) in the early 2000s, owing to a massive ministry reorganization when Junichiro Koizumi became prime minister (Nakamura, 2013). Prime Minister Koizumi held a session for cultural diplomacy and strengthened the cultural industry policy (Nakamura, 2013). The Japan Foundation (2018) is Japan's only institution dedicated to carrying out comprehensive international cultural exchange programs throughout the world. To cultivate friendship and ties between Japan and 
Table 2

Major tasks and functions of Korean PD organizations.

Source: A table was modified by the authors for this study based on sources, including Park and Lim (2014) and The Ministry of Foreign Affairs, Republic of Korea (2010).

\begin{tabular}{|c|c|c|}
\hline Major Ministry & Bureau & Performances \\
\hline \multirow[t]{3}{*}{ The Ministry of Foreign Affairs } & Headquarter & $\begin{array}{l}\text { - Establishing policy on culture, sports, tourism, adolescence and } \\
\text { education } \\
\text { - Connecting or Meditating between foreign public entities and domestic } \\
\text { bureaus }\end{array}$ \\
\hline & Korea Foundation & $\begin{array}{l}\text { - Promotion in Korean studies in abroad } \\
\text { - Cultural exchange } \\
\text { - People exchange } \\
\text { - Offering forum and policy research } \\
\text { - Publishing periodicals and short collections }\end{array}$ \\
\hline & $\begin{array}{l}\text { Korean International Cooperation } \\
\text { Agency }\end{array}$ & $\begin{array}{l}\text { - Promoting cooperative relations and mutual exchange with developing } \\
\text { countries }\end{array}$ \\
\hline \multirow[t]{7}{*}{ The Ministry of Culture, Sports and Tourism } & Headquarter & $\begin{array}{l}\text { - Generating policies in culture, art, sports, tourism, content, religion, } \\
\text { media, and public relations } \\
\text { - Promoting Korea based through policy and cultural experiences }\end{array}$ \\
\hline & $\begin{array}{l}\text { Korean Culture and Information } \\
\text { Service }\end{array}$ & - Introducing Korean culture \\
\hline & & $\begin{array}{l}\text { - Creating events for foreign lecturers } \\
\text { - Supporting foreign correspondents }\end{array}$ \\
\hline & Korea Arts\& Culture Service & $\begin{array}{l}\text { - Extending education for culture and art } \\
\text { - contribution to global culture and art education }\end{array}$ \\
\hline & Korean Film Council & - Korean film promotion \\
\hline & Korea Creative Content Agency & $\begin{array}{l}\text { - Overseeing and coordinating the promotion of the Korean content } \\
\text { industry }\end{array}$ \\
\hline & Korea Tourism Organization & Improving the global value of the Korean tourism industry \\
\hline \multirow[t]{4}{*}{ The Ministry of Education } & Headquarter & Supporting education for Koreans abroad \\
\hline & $\begin{array}{l}\text { National Institute for International } \\
\text { Education }\end{array}$ & - Supporting international Korean schools \\
\hline & & $\begin{array}{l}\text { - Accepting foreign students, supporting English public education and } \\
\text { cooperation with international education }\end{array}$ \\
\hline & The Academy of Korean Studies & - Conducting in-depth research and education of Korean culture \\
\hline $\begin{array}{l}\text { The Ministry for Agriculture, Food and } \\
\text { Rural Affairs }\end{array}$ & Headquarter & The globalization of Korean food \\
\hline
\end{tabular}

the world, the Japan Foundation creates global opportunities to foster friendship, trust, and mutual understanding through culture, language, and dialogue.

The Japan Foundation was established in October 1972 as a special legal entity supervised by the Ministry of Foreign Affairs. In October 2003, it was reorganized as an independent administrative institution. Based on a government endowment of 78 billion yen, the activities of the Japan Foundation are financed by annual government subsidies, investment revenue, and donations from the private sector.

\section{Research questions}

This study introduces a data-driven approach for assessing the practices and effectiveness of digital diplomacy in Korean and Japan. As neighboring countries, and often rivals, they have adopted similar approaches to PD. Recent PD initiatives in both countries aim to actively communicate with the foreign public and strengthen soft power (Farina, 2018; Lee, 2018). Adopting Nye's soft power concept (2004), this study comparatively assesses the performances of key PD organizations in both countries by investigating networking capability, relationship management, and public perceptions and attitudes towards a country. The research questions are given below:

RQ1: What are the network dynamics of Korean and Japanese PD organizations and the patterns of interaction among the public? In other words, how and to what extent do Korean and Japanese PD organizations engage with the public and how does the public interact with each other on Facebook?

RQ2: Who are the top influencers (e.g., authorities, hubs, and brokers) in Korean and Japanese PD networks, and to what extent do Korean and Japanese organizations manage relationships with the top influencers?

RQ3: What are the public perceptions and attitudes toward Korea and Japan expressed through comments?

By addressing these research questions, this study demonstrates an innovative analytical framework and develops measures for evaluating PD performance. First, we applied a network framework and used social network indicators to gauge networking capability, engagement with the public, and key actors among the public in the network. Second, we developed measures of PD performance by adapting Nye's (2004) soft power concept using three indicators: the attractiveness of a country's culture, political 


\section{Table 3}

Major tasks and functions of Japanese PD organizations.

Source: Data were compiled and modified by the authors for this study based on sources including the Ministry of Foreign Affairs of Japan (2012) and Japan Tourism Agency (2016).

\begin{tabular}{|c|c|c|}
\hline Major Ministry & Bureau & Performances \\
\hline \multirow[t]{2}{*}{ The Ministry of Foreign Affairs and Trade } & Headquarter & $\begin{array}{l}\text { - Establishing overall policy on culture, sports, tourism, adolescence and } \\
\text { education } \\
\text { - Connecting between foreign public entities and domestic bureaus }\end{array}$ \\
\hline & Japan Foundation & $\begin{array}{l}\text { - Promoting Japanese arts and cultural exchange, overseas Japanese-language } \\
\text { education (the JLPT exam), overseas Japanese studies and intellectual exchange }\end{array}$ \\
\hline \multirow[t]{2}{*}{$\begin{array}{l}\text { The Ministry of Education, Culture, Sports, } \\
\text { Science and Technology }\end{array}$} & $\begin{array}{l}\text { Agency for cultural } \\
\text { affairs }\end{array}$ & - Helping artists and related persons to nurture artistic activities \\
\hline & & $\begin{array}{l}\text { - Promoting regional culture, the preservation and utilization of cultural } \\
\text { properties such as national treasures and historic sites, international cultural } \\
\text { exchange, copyright protection and exploitation of works }\end{array}$ \\
\hline \multirow[t]{2}{*}{ The Japan National Tourism Organization } & Headquarter & $\begin{array}{l}\text { - To build a nation on inbound tourism initiative } \\
\text { - PR activities to promote Japanese Tourist Attractions } \\
\text { - Offering information on Tourism in Japan } \\
\text { - Tour development and marketing support } \\
\text { - Promoting Japan at overseas travel fairs }\end{array}$ \\
\hline & $\begin{array}{l}\text { Tourist information } \\
\text { Center }\end{array}$ & $\begin{array}{l}\text {-To serve international visitors with over-the-counter supplies of tourist } \\
\text { information on all of Japan in English, Chinese and Korean } \\
\text { - Distributing free brochures and maps in multiple language } \\
\text { - Collaboration with Other Tourist Information Offices } \\
\text { - National Examination for Licensed Guide-Interpreters }\end{array}$ \\
\hline \multirow{2}{*}{$\begin{array}{l}\text { The Ministry of Land, Infrastructure, Transport } \\
\text { and Tourism }\end{array}$} & Japan Tourism Agency & - Expanding international tourism exchange \\
\hline & & $\begin{array}{l}\text { - Creating appealing tourist destinations } \\
\text { - Upgrading tourism industries } \\
\text { - Promoting training and utilization of talent in the tourism field } \\
\text { - Supporting Japanese travelers abroad }\end{array}$ \\
\hline
\end{tabular}

values, and foreign policies. As the objectives of PD in both countries are to enhance soft power, measuring public perceptions and attitudes is a useful proxy for assessing the success of PD performance from the recipients' perspectives. To probe the mind of public, this study employs the text mining techniques of semantic network analysis and topic modeling. These big data analytics are particularly valuable for systemically revealing salient issues and thematic frames within the text, which hint at how different publics think and feel about a country's policies, image, culture, and diplomatic activities.

\section{Methods}

\subsection{Data collection}

The PD goals in both countries are to disseminate information about their countries, actively communicate with the foreign public, and strengthen their soft power. Facebook is considered a significant digital diplomacy platform, because it is the most popular global social media platform. We first navigated all Facebook fan pages established by PD agencies in Korea and Japan (Tables 2 and 3) and then selected the most active accounts in terms of the number of postings and public responses (e.g., comments, likes, and shares by others) for each country. As a result, the Korean Culture and Information Service (KOCIS) (www.facebook.com/ KoreaClickers), administered by MCST, was selected as a representative PD organization of South Korea. KOCIS launched its Facebook fan page on November 3, 2009, and the page had 672,928 likes in June 2018. KOCIS was established as the Overseas Information Center in 1971 to introduce Korean culture to the world. Since then, it has contributed to enhancing Korea's national image.

For Japan, we selected the Japan National Tourism Organization's (JNTO) fan page (www.facebook.com/visitjapaninternational), which had 533,066 likes in June 2018. JNTO is an independent administrative institution of the government founded in 1964 to internationally disseminate and promote information about the Japanese culture and travel to Japan (Japan National Tourism Organization (2016)) Public comments on the Facebook fan pages of KOCIS and JNTO from January 2016 to June 2017 were collected and analyzed using NodeXL, an API-based network analysis tool.

\subsection{Analysis}

\subsubsection{Social network analysis}

Social network analysis was conducted to investigate the structural characteristics of comment networks and the patterns of interaction between organizations and users as well as among users. Using UCInet, social network indicators, including multiple cohesion measures and centrality measures, were used to measure the dynamics of the networks and the strategic positions of actors embedded in the network. 
Centrality measures determine various types of network power. In-degree centrality is a measure of the ties that other nodes have initiated with a node. An actor with a high in-degree centrality score is conceptualized as an authority (Kleinberg, 1999). Out-degree centrality refers to a measure of the ties a node has initiated with other nodes. An actor with a high out-degree centrality score is conceptualized as a hub (Kleinberg, 1999). Betweenness centrality measures the number of the shortest paths between other nodes that pass through a given node (Lee et al., 2018). Actors with high betweenness centrality are regarded as brokers since they bridge or control communication between others in a network (Freeman, 1979).

\subsubsection{User profile analysis}

This study first identified the top influencers (authorities, hubs, and brokers) in each organization's comment network in terms of in-degree, out-degree, and betweenness centralities. We then manually classified influencers' demographic characteristics including their gender, type (individual or business, etc.), and geographic location. We also tracked whether they received comments from the organizations.

\section{2.3. Semantic network analysis}

A semantic network analysis, including keyword analysis and cluster analysis, was employed to examine the perceptions and attitudes expressed in the comments to the Korean and Japanese PD organizations. We obtained a total of 16,962 comments generated by 6,083 users for the Korean PD organization and a total of 8,278 comments from 4,236 users for the Japanese PD organization.

Semantic network analysis is a meaning-centered network approach for examining the relationship between textual components in contents based on the co-occurrence of words. Fulltext, a content analysis software package, was used to identify the top 100 most frequently used words and produce a co-occurrence matrix (Park \& Leydesdorff, 2004). In addition, a CONCOR (CONvergence of iterated CORrelations) analysis was conducted to uncover concurrently appearing keywords. This technique is useful in revealing hidden subgroups and the semantic structure of texts (Park, Li, \& Park, 2017). UCInet was employed for the network visualization.

\subsubsection{Topic modeling}

In addition to the semantic network analysis, we employed topic modeling using LDA (latent Dirichlet allocation) to examine the public perceptions and attitudes expressed in the comments. Based on natural language processing, topic modeling is a text summarization technique that identifies salient themes contained in the data (Diesner, Rezapour, \& Jiang, 2016). We used the ConText tool. A set of topics is obtained with a vector of words with their weights, indicating the strength of association with a given corpus. For each topic, the main words were ordered according to their fit with the topic. Topic modeling is a particularly useful technique in the field of computational social sciences, as it automatically reveals hidden topics in large volumes of text (Hagen, 2018).

\section{Results}

\subsection{Dynamics of the PD network and interaction pattern}

RQ1 asked about the network dynamics of Korean and Japanese PD organizations, the extent and pattern of their engagement with the public, and interaction among the public on Facebook. This study comparatively analyzed a comment network that appeared on the Facebook fan pages of the PD organizations in South Korea (KOCIS) and Japan (JNTO), which consisted of public comments in response to the organization's postings and replies to those comments. To reveal the configuration of a network structure and pattern of interaction among actors, various network indicators such as network density, geodesic distance, and multiple centralities were calculated on the basis of valued matrices using UCInet. Multiple cohesion measures of the binarized data matrices were also computed.

The results of the network analysis showed that both networks appear loosely connected, but KOCIS had a larger comment network than J NTO. The KOCIS network density value of 0.012 suggests that $1.2 \%$ of the total possible interactions occurred. Similarly, the JNTO network density value of 0.011 indicates that $1.1 \%$ of all possible interactions among actors took place. The KOCIS network comprised 6,084 actors with 19,012 interactions. Among the interactions, 86.13\% (16,375) were comments on KOCIS's postings and $13.87 \%(2,637)$ replies to the original comments. In the JNTO network, 4,236 actors engaged in 8,278 interactions. Similar to the KOCIS network, $86.11 \%(7,128)$ of the interactions were detected as comments on JNTO's postings, and $13.90 \%(1,151)$ were replies to the comments.

The network analysis revealed that KOCIS applied a relational and collaborative approach through which it engaged in dialogue with the public. In total, 398 of 19,012 interactions occurred between KOCIS and the public. KOCIS directly replied to commenters (199) and commented to re-commenters (199). Table 4 provides the results of the multiple cohesion measures.

In the case of KOCIS's network, the degree of centralization was 0.001 and 228 components were observed with a fragmentation value of 0.978 . The average degree was 1.006 , and the average distance in the network was 2.163 . This means that on average, each actor had around one tie, and only around two steps were necessary to reach any other randomly chosen actor in the network. The diameter value of three suggests that it took around three steps at most to reach any actor in the network. The findings also indicate that, at 0.063 , the KOCIS network exhibited a lower closure value than the JNTO network. This value represents the extent to which an actor's peers are directly connected.

The JNTO network was characterized by more centralized, fractious, and higher levels of closure than the KOCIS network. The degree of centralization was 0.003 , and 161 components were observed with a fragmentation value of 0.992 . The main component 
Table 4

Multiple cohesion measures of PD networks in KOCIS and JNTO.

Source: Definitions compiled and modified by the authors for this study based on sources including Park, Yoon, \& Leydesdorff (2016) and UCinet.

\begin{tabular}{lll}
\hline Measures & Definitions & Value of KOCIS \\
\hline Avg degree & Average number of ties each node has & Value of JNTO \\
H-Index & Largest number x such that there are x vertices of degree at least x in the underlying graph & 2 \\
Degree Centralization & Sum of the squares of the proportion of the total centrality held by each node & 1.006 \\
Components & Number of weak components & 2 \\
Components ratio & Number of components minus one divided by the number of actors minus one. \\
Connectedness & 1 minus the fragmentation & 0.001 \\
Fragmentation & Proportion of pairs of nodes that are unreachable. \\
Closure & Number of non-vacuous transitive triples divided by number of paths of length 2 \\
Avg distance & Average geodesic distance amongst reachable pairs \\
SD distance & Standard deviation of the geodesic distances amongst reachable pairs \\
Diameter & Length of the longest geodesic distance & 0.037 \\
Wiener Index & Average shortest path distance & 0.022 \\
Dependency Sum & Sum of the betweenness proportions of Y for all pairs which involve node X \\
Compactness & Mean of all the reciprocal distances & 0.978 \\
\hline
\end{tabular}

Table 5

Top authorities in the KOCIS network.

\begin{tabular}{|c|c|c|c|c|c|}
\hline Rank & Node & Indegree & Type & Gender & Location \\
\hline 1 & Korea Clickers & 6083 & Government Agency & $\mathrm{N} / \mathrm{A}$ & Korea \\
\hline 2 & Nitz Hernaez & 15 & Individual & Female & Philippines \\
\hline 3 & 赵槿芝 & 13 & Honorary reporter at KOCIS & Female & China \\
\hline 4 & Salwa Elzeny & 10 & Individual & Female & Korea \\
\hline 5 & Zackria Sait & 7 & Individual & Male & India \\
\hline 6 & Garth Moller & 7 & Individual & Male & South Africa \\
\hline 7 & Yom Min & 7 & Individual & Male & N/A \\
\hline 8 & Jeanne Theresia Kurniawan & 6 & Individual & Female & Indonesia \\
\hline 9 & Sarah Farless & 6 & Individual & Female & US \\
\hline 10 & Noilyn Alpizar Morales & 6 & Individual & Female & $\mathrm{N} / \mathrm{A}$ \\
\hline
\end{tabular}

had a diameter of one with a closure value of one, indicating "small-world" connectivity patterns and highly interconnected actors in the network (Leydesdorff \& Wagner, 2008).

\subsection{Identification of influencers and relationship management}

RQ2 addresses the top ten influencers in the Korean and Japanese PD networks and how the PD organizations manage relationships with them. In-degree, out-degree, and betweenness centralities identified authorities, hubs, and brokers respectively in the networks. If users had the same in-degree centrality value, the number of comments they received was used as a criterion to determine their rank. If users had the same out-degree centrality value, the number of comments they created was considered.

Tables 5-7 summarize the profiles of the top influencers in the KOCIS network according to centrality indices.

Noteworthy is that KOCIS was the top authority, hub, and broker with the highest in-degree $(6,083)$, out-degree (160), and betweenness centrality $(36,980,134)$. In the KOCIS network, the top authorities were mostly individual users, more females than males, and residents of East and South Asia (Table 5). Among them, 赵槿芝 was a Chinese resident who worked as an honorary

Table 6

Top hubs in the KOCIS network.

\begin{tabular}{|c|c|c|c|c|c|}
\hline Rank & Node & Outdegree & Type & Gender & Location \\
\hline 1 & Korea Clickers & 160 & Government agency & N/A & Korea \\
\hline 2 & Nuri Sejonghakdang & 34 & Individual & Female & Philippines \\
\hline 3 & 박순옥 & 34 & Individual & Female & Korea \\
\hline 4 & Mikesglobaladventures & 22 & Individual & Male & N/A \\
\hline 5 & Sarah Farless & 19 & Individual & Female & US \\
\hline 6 & PJ Douglas & 12 & Individual & Male & N/A \\
\hline 7 & Salwa Elzeny & 11 & Individual & Female & Korea \\
\hline 8 & Loura Al Kurdi & 9 & Individual & Female & Syria \\
\hline 9 & 赵槿芝 ～～～～～～～～ & 6 & Honorary reporter at KOCIS & Female & China \\
\hline 10 & Yostina Wasef & 6 & Honorary reporter at KOCIS & Female & Egypt \\
\hline
\end{tabular}


Table 7

Top brokers in the KOCIS network.

\begin{tabular}{|c|c|c|c|c|c|}
\hline Rank & Node & Betweeness & Type & Gender & Location \\
\hline 1 & Korean Clickers & 36980134 & Government agency & $\mathrm{N} / \mathrm{A}$ & Korea \\
\hline 2 & Nuri Sejonghakdang & 528.000 & Individual & Female & Philippines \\
\hline 3 & 박순옥 & 524.000 & Individual & Female & Korea \\
\hline 4 & Sarah Farless & 231.000 & Individual & Female & US \\
\hline 5 & Mikesglobaladventures & 208.667 & Individual & Male & $\mathrm{N} / \mathrm{A}$ \\
\hline 6 & Salwa Elzeny & 112.333 & Individual & Female & Korea \\
\hline 7 & Nitz Hernaez & 88.167 & Individual & Female & Philippines \\
\hline 8 & 赵槿芝 & 86.667 & Honorary reporter at KOCIS & Female & China \\
\hline 9 & PJ Douglas & 55.000 & Individual & Male & US \\
\hline 10 & Loura Al Kurdi & 28.000 & Individual & Female & Syria \\
\hline
\end{tabular}

reporter at KOCIS. Interestingly, half the authorities received replies from KOCIS, suggesting that the Korean government actively conversed with authorities in the network.

The top hubs were mostly individual female users and residents of East Asia and other regions including North America, the Middle East, and Africa (Table 6).

Interestingly, two users (박순옥 and Sarah Farless) were Koreans, and one was living in the US. Other hubs were members of the foreign public, among which three (Loura Al Kurdi, 赵槿芝, and Yostina Wasef) were honorary reporters and former workers at KOCIS. KOCIS replied to two of these hubs' comments. The top brokers were also predominantly individual female users living in East Asia (Table 7).

The brokers were Koreans, a foreigner living in Korea, or members of the foreign public in other countries. Noteworthy is that many brokers were also an authority or a hub, suggesting that few public influencers disseminate, control, and leverage information in the diplomacy network. Three brokers received replies from KOCIS. One, 赵槿芝, who was also an authority and hub, worked as an honorary reporter at KOCIS. The other hub, Loura Al Kurdi, was a former worker at KOCIS. The Pearson correlation analysis confirmed very strong significant correlations among the in-degree, out-degree, and betweenness centralities $(p<.01)($ Table 8$)$.

Table 8

Correlations between network centrality values in KOCIS.

\begin{tabular}{llll}
\hline & Indegree & Outdegree & Betweenness \\
\hline Indegree & - & $.922^{* *}$ & $1.000^{* *}$ \\
Outdegree & & - & $.921^{* *}$ \\
Betweenness & & & - \\
\hline
\end{tabular}

Note. ${ }^{* *}$ significant at $p<.01$

Fig. 1 displays a directed network comprising KOCIS and the top influencers.

Using the Clauset-Newman-Moore algorithm, four clusters were revealed. The color of the node represents a group, and the node size was adjusted on the basis of in-degree centrality. A larger node indicates receipt of more comments from other users in the entire network. A link between nodes represents comments to each other. A green link refers to interactions between KOCIS and the top influencers, while red links refer to interactions between the top influencers. Solid lines represent strong ties with a tie strength value greater than 5 . Weak ties are indicated as dotted lines. Interestingly, the top influencers not only actively interacted with KOCIS but also exchanged their thoughts and opinions with other influencers. In total, 19 influencers had 1,727 ties with 14 unique ties. The network density was 0.117 , with an average geodesic distance value of 1.717 .

Tables 9-11 summarize the top influencers in the JNTO network. Similar to KOCIS, JNTO had the highest in-degree centrality $(4,235)$ and betweenness centrality $(17,928,426)$, but very low out-degree centrality $(0)$. The top authorities in the JNTO network were mostly individual users, with more females than males.

They were members of the foreign public living in Oceania and Southeast Asia (Table 9). The top hubs were business users, such as travel and accommodation agencies, as well as education institutions, located in Japan, Southeast Asia, and Europe (Table 10). The top brokers were also predominantly business users or individuals, and they were mostly female (Table 11). Similar to the KOCIS network, most brokers were either authorities or hubs. The Pearson correlation analysis suggests very strong significant correlations between in-degree and betweenness centralities $(p<.01)$ (Table 12). Unlike the Korean government agency, the Japanese agency did not provide any feedback to the top influencers. Fig. 2 displays a directed network comprising JNTO and the top influencers.

The same visualization option used in the KOCIS network was applied to JNTO. Using the Clauset-Newman-Moore algorithm, five clusters were identified. Interestingly, the top influencers not only actively interacted with JNTO but also exchanged their thoughts and opinions with other influencers. In total, 20 influencers generated 262 ties with 7 unique ties. The network density was 0.066 with an average geodesic distance value of 1.78 . 


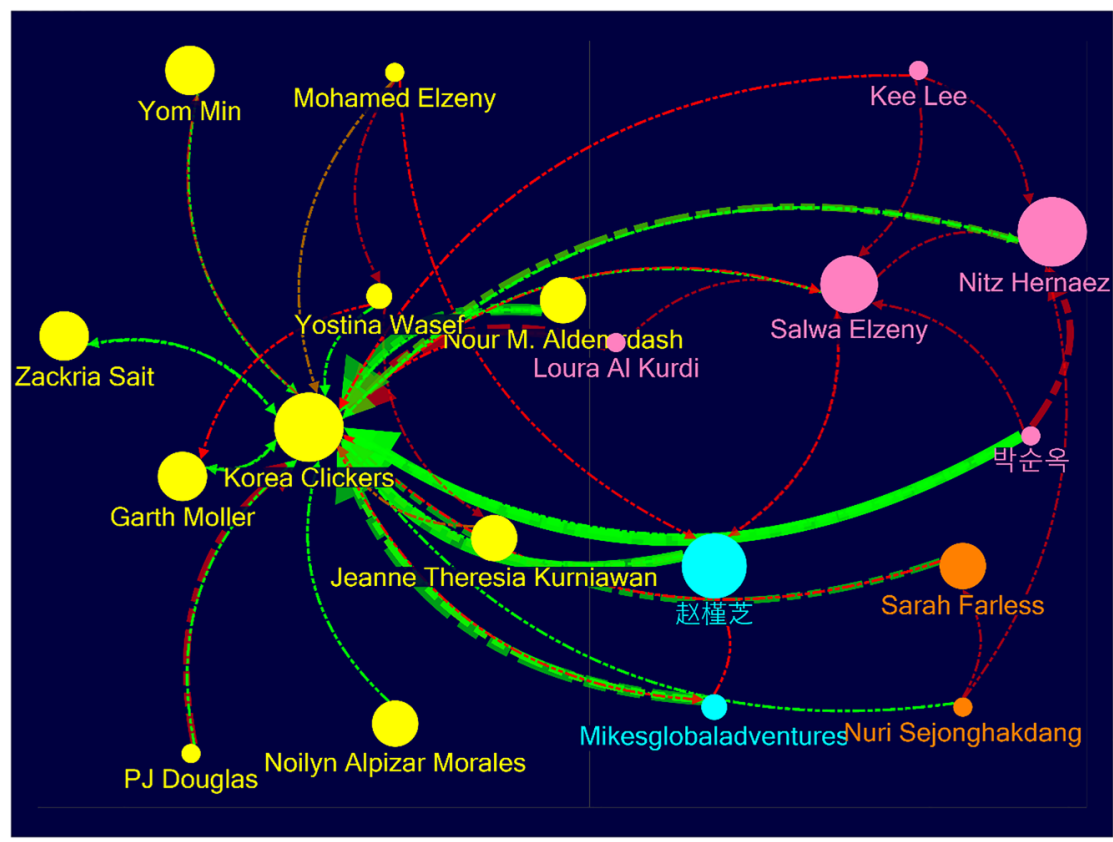

Fig. 1. Top influencer network in KOCIS.

Table 9

Top authorities in the JNTO network.

\begin{tabular}{llllll}
\hline Rank & Node & Indegree & Type & Gender & Location \\
\hline 1 & Visit Japan & 4235 & Government agency & N/A & Japan \\
2 & Beatrix Dadic & 8 & Individual & Female & Female \\
3 & Maria Zainori & 5 & Individual & Female \\
4 & Cassa Blanca & 5 & Individual & Female & N/A \\
5 & Ves Prim & 4 & Individual & Female \\
6 & Eva Marie & 4 & Individual & Male & N/A \\
7 & Oscar Trevino & 4 & Individual & Male & N/A \\
8 & Masayuki Uzaki & 4 & Individual & Female & Male \\
9 & Ruth Chan & 4 & Individual & N/A \\
10 & Enrico Pizzoli & 4 & Individual & Male \\
\hline
\end{tabular}

Table 10

Top hubs in the JNTO network.

\begin{tabular}{|c|c|c|c|c|c|}
\hline Rank & Node & Outdegree & Type & Gender & Location \\
\hline 1 & Study English in the Philippines & 4235 & Business & $\mathrm{N} / \mathrm{A}$ & Philippines \\
\hline 2 & Shiga Palace Hotel & 8 & Business & $\mathrm{N} / \mathrm{A}$ & Japan \\
\hline 3 & Guide Poznań & 5 & Business & $\mathrm{N} / \mathrm{A}$ & Poland \\
\hline 4 & Hakone Travel & 5 & Business & $\mathrm{N} / \mathrm{A}$ & Japan \\
\hline 5 & Zen Guillen-Takei & 4 & Individual & Female & N/A \\
\hline 6 & Steve Bridgeman & 4 & Individual & Male & N/A \\
\hline 7 & Nur Hanis Mohamad Hanapi & 4 & Individual & Female & Malaysia \\
\hline 8 & Hila Abargil & 4 & Individual & Female & $\mathrm{N} / \mathrm{A}$ \\
\hline 9 & Tom Tzabar Hamabi & 4 & Individual & Female & $\mathrm{N} / \mathrm{A}$ \\
\hline 10 & Azira Zulkafley & 4 & Individual & Male & $\mathrm{N} / \mathrm{A}$ \\
\hline
\end{tabular}

\subsection{Public perceptions and attitudes as perceived soft power}

\subsubsection{Public perceptions and attitudes toward Korean PD organizations}

The semantic network analysis revealed that the most frequently used keyword in the KOCIS network was "Korea" (1,443), followed by "beautiful" (860), "love” (827), "thank" (600), “wow” (547), "congrats" (514), "Korean" (490), "go" (479), "nice” (470), and "good" (467). Table 13 presents the popular keyword pairs in terms of their co-occurrence in the comments. 
Table 11

Top brokers in the JNTO network.

\begin{tabular}{|c|c|c|c|c|c|}
\hline Rank & Node & Betweenness & Type & Gender & Location \\
\hline 1 & Visit Japan International & 4235 & Organization & $\mathrm{N} / \mathrm{A}$ & Japan \\
\hline 2 & Study English in the Philippines & 8 & Business & N/A & Philippines \\
\hline 3 & Shiga Palace Hotel & 5 & Business & N/A & Japan \\
\hline 4 & Guide Poznań & 5 & Business & $\mathrm{N} / \mathrm{A}$ & Poland \\
\hline 5 & Hakone Travel & 4 & Business & N/A & Japan \\
\hline 6 & Beatrix Dadic & 4 & Individual & Female & Australia \\
\hline 7 & Cassa Blanca & 4 & Individual & Female & Singapore \\
\hline 8 & Masayuki Uzaki & 4 & Individual & Male & $\mathrm{N} / \mathrm{A}$ \\
\hline 9 & Zen Guillen-Takei & 4 & Individual & Female & $\mathrm{N} / \mathrm{A}$ \\
\hline 10 & Maria Zainori & 4 & Individual & Female & $\mathrm{N} / \mathrm{A}$ \\
\hline
\end{tabular}

Table 12

Correlation between network centrality values for JNTO.

\begin{tabular}{llll} 
& Indegree & Outdegree & Betweenness \\
\hline Indegree & - & -0.022 & $1.000^{* * *}$ \\
Outdegree & & - & -0.024 \\
Betweenness & & & - \\
\hline
\end{tabular}

Note. $* *$ significant at $p<.01$.

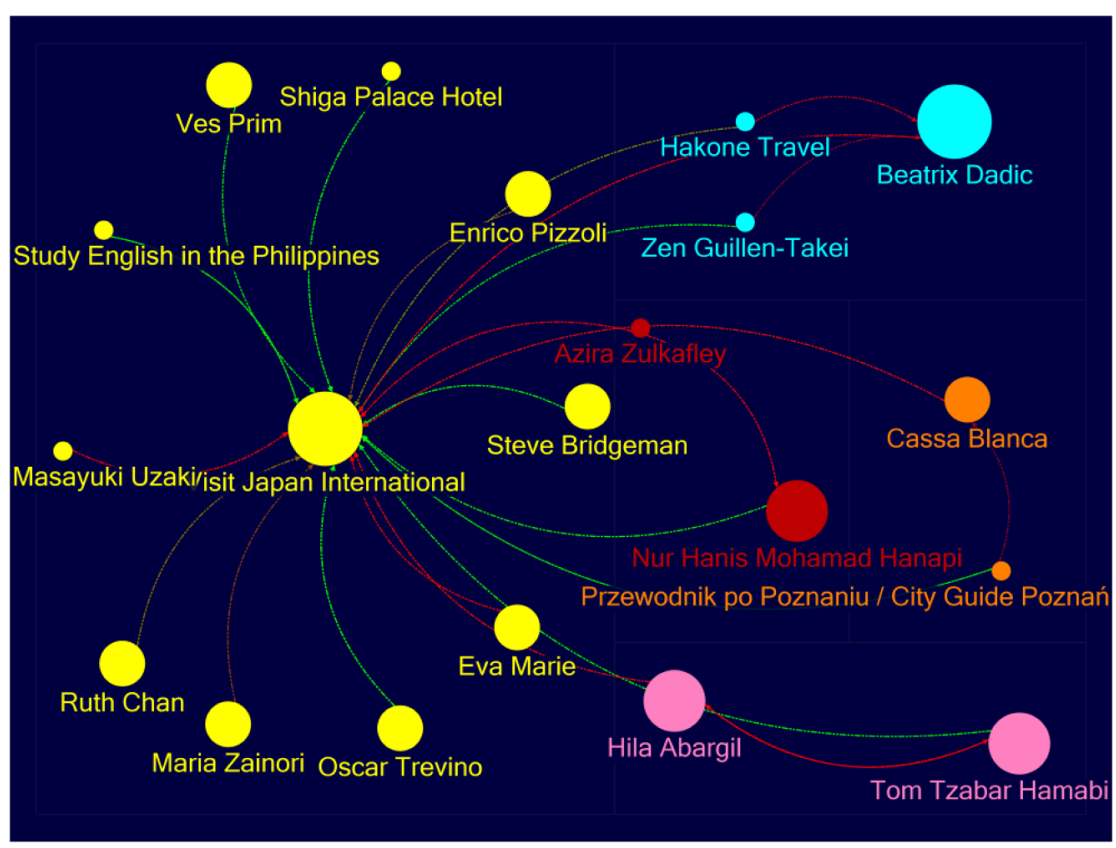

Fig. 2. Top influencer network for JNTO.

In light of the dominant hateful sentiments of the domestic public toward the government's diplomatic approach at that time and the harsh criticism of former president Guen-hye Park's qualifications, the semantic network analysis results are surprising (Daily Sabah, 2016). As indicated by the popular word pairs "Korea-president" and "beautiful-president," the foreign public not only strongly associated the nation with former president Park but also identified her in terms of her feminine appearance in a favorable way. The CONCOR analysis identified four clusters in the semantic network (Fig. 3).

The themes found in each cluster were "attractiveness of the country and Korean people (green)," "interest in and blessings for former president Park (red)," "liking Korea and its culture (yellow)," and "interest in Korean culture such as its fashion, food, and travel (blue)."

In addition to the semantic network analysis, a topic model using LDA explored the entire corpus of comments made on KOCIS's postings to reveal the five main topics, which were represented by seven words, and the weight of each topic in the comments (Table 14). 
Table 13

Top keyword pairs in the comments of the KOCIS network.

\begin{tabular}{|c|c|c|c|c|c|}
\hline Word 1 & Word 2 & Tie Weight & Word 1 & Word 2 & Tie Weight \\
\hline beautiful & korea & 1131455 & great & korea & 334750 \\
\hline korea & love & 1087268 & korea & south & 333411 \\
\hline korea & thank & 794027 & beautiful & go & 321100 \\
\hline korea & korean & 696280 & korea & see & 316004 \\
\hline korea & wow & 694941 & god & korea & 311987 \\
\hline beautiful & love & 686140 & go & love & 308560 \\
\hline korea & nice & 626652 & korean & thank & 308360 \\
\hline good & korea & 625313 & thank & wow & 307767 \\
\hline korea & like & 605228 & amazing & korea & 299936 \\
\hline go & korea & 508820 & korea & wish & 297258 \\
\hline beautiful & thank & 501085 & korea & park & 295919 \\
\hline love & thank & 481516 & korea & miss & 285207 \\
\hline beautiful & korean & 439400 & nice & thank & 277524 \\
\hline beautiful & wow & 438555 & good & thank & 276931 \\
\hline korean & love & 422240 & country & korea & 273156 \\
\hline love & wow & 421428 & korean & wow & 269880 \\
\hline korea & want & 407056 & like & thank & 268036 \\
\hline korea & president & 401700 & happy & korea & 262444 \\
\hline beautiful & nice & 395460 & haha & korea & 261105 \\
\hline beautiful & good & 394615 & day & korea & 257088 \\
\hline beautiful & like & 381940 & beautiful & want & 256880 \\
\hline love & nice & 380016 & korea & look & 255749 \\
\hline good & love & 379204 & beautiful & president & 253500 \\
\hline korea & place & 368225 & best & korea & 251732 \\
\hline like & love & 367024 & love & want & 246848 \\
\hline
\end{tabular}

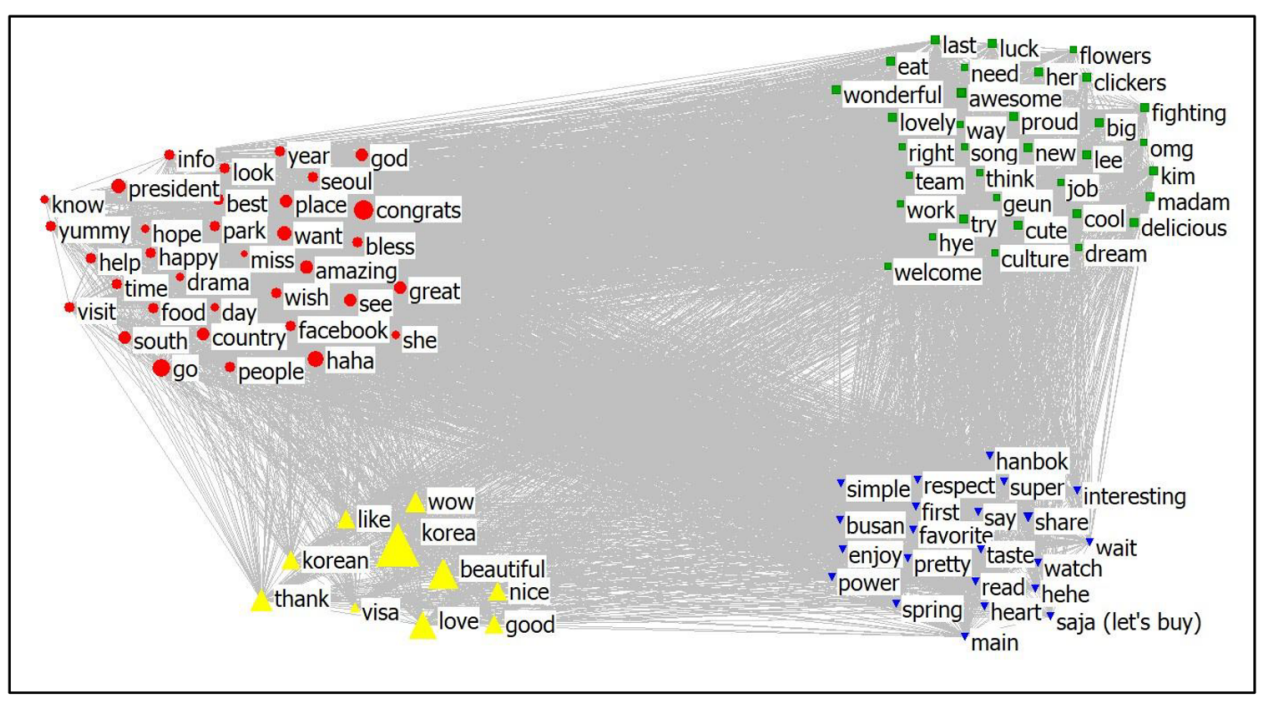

Fig. 3. Semantic network of comments for KOCIS.

Table 14

Topic modeling of comments in KOCIS.

\begin{tabular}{llc}
\hline Topic & Weight & Topic members \\
\hline Interest in events promoted by KOCIS and Korean culture & 1.882276 & korean - topic - enough - sad - event - forever - love \\
Celebrating the female president appointment & 0.335259 & korea - love - nice - good - place - congratulations - park \\
Liking former President and culture & 0.150202 & beautiful - korean - president - great - facebook - god - food \\
Tourism attraction & 0.138533 & bless - wonderful - day - fighting - lot - me - busan \\
Satisfied trip experience in Korea & 0.135066 & amazing - info - time - corea - happy - cool - lee \\
\hline
\end{tabular}


Table 15

Top keyword pairs in the comments for the JNTO network.

\begin{tabular}{|c|c|c|c|c|c|}
\hline Word 1 & Word 2 & Tie weight & Word 1 & Word 2 & Tie weight \\
\hline japan & beautiful & 431298 & beautiful & year & 108558 \\
\hline japan & love & 303408 & go & love & 105264 \\
\hline japan & visit & 300762 & visit & go & 104346 \\
\hline japan & go & 269892 & japan & new & 102312 \\
\hline japan & place & 246960 & japan & day & 101430 \\
\hline japan & like & 223146 & beautiful & thank & 96822 \\
\hline japan & year & 195804 & love & place & 96320 \\
\hline japan & thank & 174636 & japan & tokyo & 96138 \\
\hline beautiful & love & 168216 & japan & sakura & 96138 \\
\hline beautiful & visit & 166749 & japan & excellent & 96138 \\
\hline japan & good & 164934 & visit & place & 95480 \\
\hline japan & see & 163170 & japan & country & 92610 \\
\hline japan & japanese & 153468 & japan & hope & 91728 \\
\hline beautiful & go & 149634 & beautiful & good & 91443 \\
\hline japan & want & 149058 & japan & blossoms & 90846 \\
\hline japan & time & 147294 & beautiful & see & 90465 \\
\hline beautiful & place & 136920 & love & like & 87032 \\
\hline japan & amazing & 133182 & japan & page & 86436 \\
\hline japan & nice & 124362 & visit & like & 86273 \\
\hline beautiful & like & 123717 & go & place & 85680 \\
\hline japan & look & 123480 & beautiful & japanese & 85086 \\
\hline japan & best & 119952 & japan & need & 84672 \\
\hline visit & love & 117304 & beautiful & want & 82641 \\
\hline japan & people & 112896 & beautiful & time & 81663 \\
\hline japan & miss & 109368 & japan & cherry & 79380 \\
\hline
\end{tabular}

The findings indicate similar topics to the themes uncovered in the semantic network analysis. The most popular topic was interest in the various cultural events promoted by KOCIS and Korean culture such as food, drama, and the Korean people. In its postings, KOCIS often delivered information and boosted participation in the cultural events it hosted, such as the Paralympic national team's training ceremony or celebrating the Lunar New Year's Day at tourism attractions such as Gyeongbokgung Palace and the National Folk Museum of Korea. The other topics were related to celebrating the first female president in Korea and expressing their liking of former president Park. Furthermore, some topics shared travel information and pleasurable personal experiences in Korea.

\subsubsection{Public perceptions and attitudes toward the Japanese PD organization}

As expected, the most frequently used keyword in the JNTO network was "Japan" (871), followed by "beautiful" (491), "visit" (439), "go" (388), "love" (344), "place" (278), "like” (251), "good" (188), "see” (185), and "year" (184). Table 15 summarizes the popular keyword pairs in the comments.

The top keyword pairs suggest that, similar to the results of the semantic network, the public perceived Japan as a beautiful country and attributed this positive emotion to tourist attractions they visited, such as Tokyo, and natural scenery, such as the cherry blossoms (sakura in Japanese).

The CONCOR analysis revealed four clusters in the JNTO semantic network (Fig. 4).

Themes that emerged in the cluster were "liking tourism attractions" (blue); "attractiveness of the country, people, and nature" (yellow); "satisfied with the travel experience and plan to visit in the future" (green); and "sharing personal experiences" (red).

We also employed a topic model with five topics using LDA. The results indicate the representative word lists of five topics and the weight of each in the comments on the JNTO postings (Table 16).

In line with the results of the semantic network analysis, the topics identified in the comments mostly expressed favorable emotions and impressions of the nation, its beautiful nature, information about tourism attractions, and satisfactory visit experiences.

\section{Discussion and conclusion}

Adopting Nye's soft power approach, this study proposed social media metrics to assess the capacity of PD organizations to engage with the public, their networking power, and public perceptions and attitudes toward a country. Using the cases of Korea and Japan, the study provided a non-Western perspective and insights into the status quo of digital diplomacy in East Asian countries.

We first investigated network dynamics and patterns of interactions in each organization's comment network. The results indicate that the Korean PD organization-KOCIS—generated a larger, more loosely connected, and decentralized comment network than the Japanese PD organization JNTO, which presented a "small-world" connectivity pattern with highly interconnected actors in the network. This implies that the Korean government adopted the notion of new PD by representing the decentralized mode of communication from diverse participants, which may boost collaboration in policy-making processes (Fisher, 2010). 


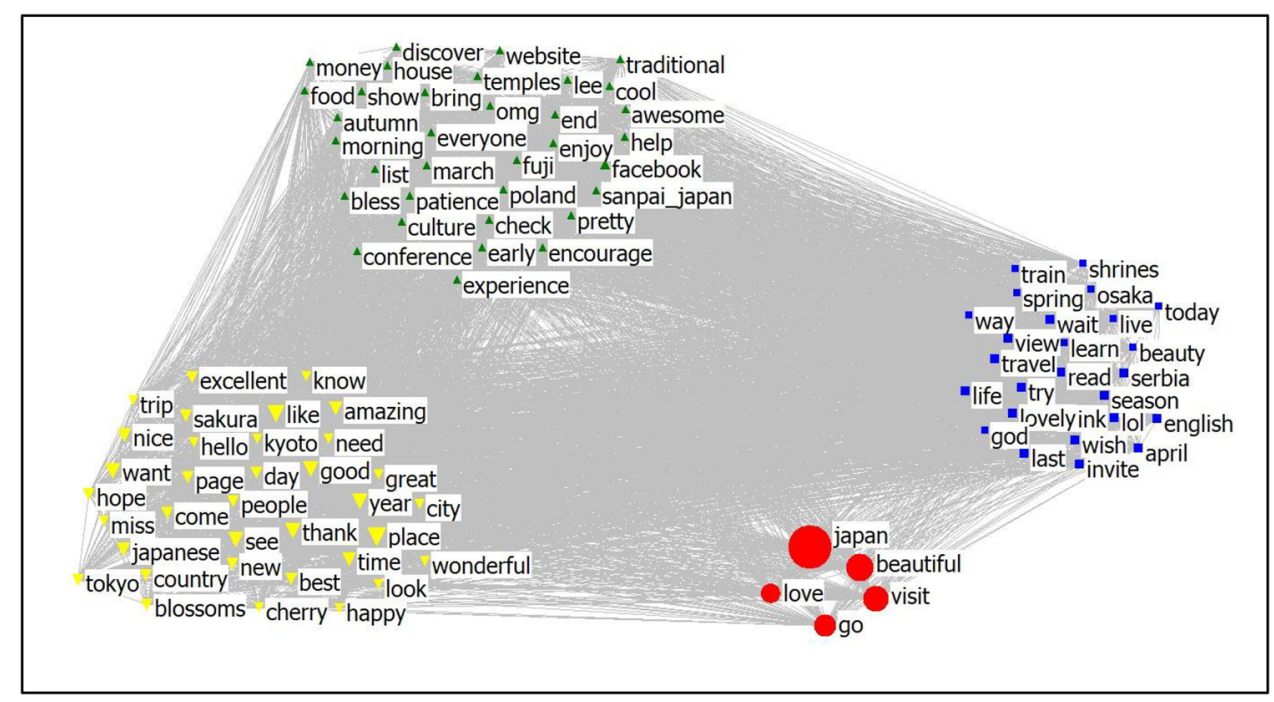

Fig. 4. Semantic network of comments for JNTO.

Table 16

Topic modeling of comments in the JNTO network.

\begin{tabular}{lll}
\hline Topic & Weight & Topic Members \\
\hline Liking Japan and trip in Japan & 2.189416 & japan - beautiful - love - visit - place - year - japanese \\
Trip information and experience & 0.733963 & kobe - google - I - natural - voyage - picture - fit \\
Tourism attraction and interest & 0.403098 & find - left - town - village - letter - izumo - making \\
Interest in culture & 0.278981 & culture - auntie - pray - with - tom - from - tohoku \\
Impression to the nature and places & 0.247749 & site - nature - communication - improve - wonderful - sites - missing \\
\hline
\end{tabular}

The Korean government also successfully managed relationships with the top influencers in its network by providing feedback to their comments. This implies that the Korean PD organization systemically monitored the conversational threads relayed by users and further enriched such discussions, playing the roles of discussion initiator and real-time facilitator. In contrast, no interaction between JNTO and users was observed in its comment network, implying that the Japanese PD organization still uses social media as a mere information dispersion tool and has failed to build a meaningful connection with key influencers. These results are consistent with the findings of previous study conducted by Park and Lim (2014), which warned that Japanese PD organizations had not improved their ineffective social media approach. We also found that Japanese agencies mostly lacked an English-language social media presence.

Interestingly, in the KOCIS network, the key influencers who actively generated information and expressed their thoughts (high out-degree centrality) were also more likely to receive feedback from others (high in-degree centrality), and bridged communication among other users (high betweenness centrality). Similarly, an authority in the JNTO network also played the role of broker in the network. This result highlights the importance of classifying and scrutinizing influencers' activities and the content they produce in a communications network (Park, Park, Lim, \& Park, 2016).

Furthermore, it was confirmed that several key influencers were foreign individuals who participated in KOCIS's diplomacy program as "honorary reporters." This provides evidence of the effectiveness of the government's collaborative PD programs, in which it encourages the foreign public to promote Korea online by sharing their cultural experiences to educate others about the country. This fits the notion of new PD, in that the Korean government has not only effectively interacted with different communities but also bridged the domestic and foreign public in executing PD (Fisher, 2010; Zaharna, 2005).

In addition to social network analysis, one of the innovative contributions of this study is its combination of two computational methods (semantic network analysis and topic modeling) with big data to measure public perceptions and attitudes from large-scale textual data. The findings from the two analyses suggest similar themes, topics, and words in the comments, although their algorithms for processing the data differ. For example, in the KOCIS network, the foreign public expressed their attraction to Korea and its culture, as well as favorable attitudes toward former president Guen-hye Park. Although at that time the domestic public climate toward her diplomatic strategy, recognized as superficial fashion diplomacy, was very negative and skeptical, the foreign public positively perceived her as a feminine political icon and supported her endeavors to build international networks (Daily Sabah, 2016). Similarly, in the JNTO network, the foreign public voiced their positive feelings toward Japan, its nature, Japanese culture, and interest in travel attractions.

These findings lead to the conclusion that Korean digital diplomacy is well grounded in the notion of networked PD, while Japan's digital diplomacy is still in its infancy and limited in information provision, focusing mostly on tourism assets. In the case of Korea, perceived soft power from the foreign public was observed in articulations of its various cultural assets and political values 
(Gilboa, 2008a, Nye, 2004). For Japan, it was more focused on tourism, and the favorable public perception of the nation and culture indicates the country's soft power.

This study provides important theoretical and methodological insights for the evaluation of digital diplomacy practices, and measures public perceptions and attitudes using big data obtained from social media. The research demonstrated that the combination of semantic network analysis and topic modeling is useful for systemically investigating large-scale text on the web from different angles. Important is that topic modeling can complement the limitations of a semantic network analysis, which only analyzes the top keyword matrices.

Compared to traditional content analysis employed in a few digital diplomacy studies, this research demonstrated how to map networking patterns and automatically reveal the salient themes in information based on public comments on social media. The findings can help diplomacy practitioners monitor and measure agencies' networking power, relationship management, and public perceptions and attitudes toward their diplomacy programs.

Although this study introduced innovative techniques to assess digital diplomacy practices, it is not without limitations. First, automatic content analysis tools need contextual knowledge about the situations in which the keywords are used, and they require careful interpretation. In particular, to make sense of word pairs that can imply more than one meaning, researchers should check the full sentences that include those pairs and confirm their meaning.

Second, while the study only considered Facebook, the organizations have other web platforms on which they promote their programs. A future study should investigate different social media platforms to enhance the understanding of digital diplomacy practices and public perceptions and attitudes. Public opinion and sentiment may differ across different online communities. In addition, this study analyzed only one PD organization-a tourism agency-from each country. Given the nature of tourism agencies, the organizations tended to focus on outward appearances or promoting the culture rather than discussing domestic politics or issues. Although image-based PD is a long-running problem in Korean and Japanese PD, this may limit opportunities to get more policyrelated feedback from the public. Thus, the findings are not generalizable to the activities of other PD institutions. Future studies should consider these limitations and seek to expand the study subjects.

\section{Supplementary materials}

Supplementary material associated with this article can be found, in the online version, at doi:10.1016/j.ipm.2018.10.021.

\section{References}

Ayhan, K. (2018). Editorial: Special issue on soft power and public diplomacy in East Asia. Journal of Contemporary Eastern Asia, $17(1)$, 1-4.

Barnett, G., \& Raymond, D. (2005). Power in international politics. International Organization, 59(1), 39-75. https://doi.org/10.1017/S0020818305050010.

Barnett, G., Xu, W. W., Chu, J., Jiang, K., Huh, C., Park, J. Y., et al. (2017b). Measuring international relations in social media conversations. Government Information Quarterly, 34(1), 37-44.

Barnett, G. A., Ruiz, J. B., Xu, W. W., Park, J. Y., \& Park, H. W. (2017a). The world is not flat: Evaluating the inequality in global information gatekeeping through website co-mentions. Technological Forecasting \& Social Change, 117, 38-45.

Buhmann, A. (2016). Measuring country image: Theory, method, and effects. Springer Fachmedien Wiesbaden; Fribourg.

Cho, Y. Y. (2012). Public diplomacy and South Korea's strategies. The Korean Journal of International Studies, 10(2), 275-296.

Chung, M. (2017). Not just numbers: The role of social media metrics in online news evaluations. Computers in Human Behavior, 75, $949-957$.

Criado, J. I., Sandoval-Almazan, R., \& Gil-Garcia, J. R. (2013). Government innovation through social media. Government Information Quarterly, 30(4), 319-326.

Daily Sabah (2016, October 23). Fashion diplomacy: More than simply a wardrobe choice. Daily Sabah. Retrieved from https://www.dailysabah.com/feature/2016/ 10/24/fashion-diplomacy-more-than-simply-a-wardrobe-choice.

Diesner, J., Rezapour, R., \& Jiang, M. (2016). Assessing public awareness of social justice documentary films based on news coverage versus social media. IConference 2016 Proceedings.

Farina, F. (2018). Japan's gastrodiplomacy as soft power: Global washoku and national food security. Journal of Contemporary Eastern Asia, 17(1), 131-146.

Fisher, A. (2010). Mapping the great beyond: Identifying meaningful networks in public diplomacy. USC center on public diplomacy. CPD Perspectives on Public Diplomacy, 2, 1-87.

Fitzpatrick, K. (2013). Public diplomacy and ethic: From soft power to social conscience. In R. S. Zaharna, A. Arsenault, \& A. Fisher (Eds.). Relational, networked and collaborative approaches to public diplomacy: The connective mindshift (pp. 29-43). New York: Routledge.

Gilboa, E. (2008a). Searching for a theory of public diplomacy. The Annals of the American Academy of Political and Social Science, 616(1), 55-77.

Gilboa, E. (2008b). Media diplomacy. In W. Donsbach (Ed.). Encyclopedia of communication (pp. 2852-2857). London: International Communication Association/ Blackwell Publishing.

Gregory, B. (2011). American public diplomacy: Enduring characteristics, elusive transformation. Hague Journal of Diplomacy, 6(3-4), 351-372.

Gullion, E. (1965). Edward R. Murrow Center for Public Diplomacyhttp://fletcher.tufts.edu/Murrow/Diplomacy.

Hagen, L. (2018). Content analysis of e-petitions with topic modeling: How to train and evaluate LDA models? Information Processing \& Management, 54, $1292-1307$. Jang, G., \& Paik, W. (2012). Korean waves as tool for Korea's new cultural diplomacy. Advances in Applied Sociology, 2, $196-202$.

Japan National Tourism Organization. (2016). Press release. Retrieved from http://www.jnto.go.jp/jpn/news/press_releases/pdf/20160119_1.pdf.

Japan Tourism Agency. (2016). The Consumption trend survey for foreigners visiting Japan. Retrieved from http://www.mlit.go.jp/common/001032143.pdf.

Jung, G., \& Yoon, S. (2009). The meaning of Japan's public diplomacy on South Korea: Focus on the Japan foundation and the Japan international cooperation agency. Study of International Issues, 9(1), 137-182.

Kavanaugh, A., Fox, E. A., Sheetz, S., Yang, S., Li, L. T., Whalen, T., Shoemaker, D., Natsev, P., \& Xie, L. (2011). Social media use by government: From the routine to the critical. The proceedings of the 12th annual international conference on digital government research (pp. 121-130). .

Kim, E. M. (2011). The role of the govenment in cultural industry: Some observations from Korea's experience. Keio Communication Review, 33, 163-182.

Kim, H. J. (2018). Multi-stakeholders in public and cultural diplomacies as seen through the lens of public-private partnerships: A comparative case study of Germany and South Korea. Journal of Contemporary Eastern Asia, 17(1), 68-94.

Kim, M., Heo, Y. C., Choi, S. C., \& Park, H. W. (2014). Comparative trends in global communication networks of \#K-pop tweets. Quality \& Quantity, 48(5), 2687-2702.

Kleinberg, J. M. (1999). Authoritative sources in a hyperlinked environment. Journal of the ACM, 46(5), 604-632.

Korea Focus (2015). Korea's public diplomacy needs better coordination and strategies. Korea Focus(January) Retrieved from.

Kuzma, J. (2010). Asian government usage of web 2.0 social media. European Journal of ePractice, 9, 1-13.

Lee, G. (2009). A theory of soft power and Korea's soft power strategy. Korean Journal of Defense Analysis, 21(2), 205-218. 
Lee, H., Chung, N., \& Nam, Y. (2018). Do online information sources really make tourists visit more diverse places?: Based on the social networking analysis. Information Processing \& Management.

Lee, J. N. (2008). The rise of China and soft power: China's soft power influence in Korea. China Review, 8(1), $127-154$.

Lee, K. S. (2018). The making of a nation's citizen diplomats: Culture-learning in international volunteer training program. Journal of Contemporary Eastern Asia, 17(1), 94-112.

Leonard, M. (2002). Public diplomacy. London, England: Foreign Policy Centre.

Leydesdorff, L., \& Wagner, C. S. (2008). International collaboration in science and the formation of a core group. Journal of Informetrics, 2(4), 317-325.

Manor, I. (2016). Are we there yet: Have MFAs realized the potential of digital diplomacy? Results from cross-national comparison. Leiden, Netherlands: Brill.

McGray, D. (2009). Japan's gross national cool. Foreign Policy, 130. Retrieved from https://foreignpolicy.com/2009/11/11/japans-gross-national-cool/.

Melissen, J. (2005). The new public diplomacy: Between theory and practice. London, England: Palgrave Macmillan.

Melissen, J., \& Keulenaar, E. V. (2017). Critical digital diplomacy as a global challenge: The South Korean experience. Global Policy, 8(3), $294-302$.

Meza, X. V., \& Park, H. W. (2015). Globalization of cultural products: A webometric analysis of Kpop in Spanish-speaking countries. Quality \& Quantity, 49(4), $1345-1360$.

Michal, D. (2009). Japan brand strategy: The taming of 'Cool Japan' and the challenges of cultural planning in a postmodern age. Social Science Japan Journal, 12(2), $247-266$.

Ministry of Foreign Affairs and Trade in South Korea (2010). Manual on cultural diplomacy.

Ministry of Foreign Affairs of Japan. Retrieved from https://www.mofa.go.jp, 2018. Ministry of Foreign Affairs, Republic of Korea, Manual on cultural diplomacy, Retrieved from http://www.mofa.go.kr, 2010. Ministry of Foreign Affairs, Republic of Korea, Enforcement decree of the republic diplomacy act, Retrieved from http://www.mofa.go.kr, 2016.

Nakamura, T. (2013). Japan's new public diplomacy: Coolness in foreign policy objectives. Media and Society, 5, 1-23.

Nye Jr, J. S. (2004). Soft power and american foreign policy. Political Science Quarterly, 119(2), 255-270.

Nye, J. S., Jr (2008). Public diplomacy and soft power. The Annals of the American Academy of Political and Social Science, 616(1), 94-109.

Pamment, J. (2014). Articulating influence: Toward a research agenda for interpreting the evaluation of soft power, public diplomacy and nation brands. Public Relations Review, 40(1), 50-59.

Park, H. W., Yoon, J., \& Leydesdorff, L. (2016). The normalization of co-authorship networks in the bibliometric evaluation: The government stimulation programs of China and Korea. Scientometrics, 109(2), 1017-1036.

Park, S., Li, H., \& Park, H. W. (2017). Can sustainability information on corporate website reflect CSR strategies?: A semantic network analysis of top companies in South Korea and China. Journal of the Korean Data Analysis Society, 19(1), 43-54.

Park, S., \& Lim, Y. S. (2014). Information networks and social media use in public diplomacy: A comparative analysis of South Korea and Japan. Asian Journal of Communication, 24(1), 79-98.

Park, S., Park, J. Y., Lim, Y. S., \& Park, H. W. (2016). Expanding the presidential debate by tweeting: The 2012 presidential election debate in South Korea. Telematics and Informatics, 33(2), 557-569.

Sam, M. U., Song, J., \& Moore, D. (2012). Korea's Public Diplomacy: A new initiative for the future. Issue briefs, 39. Retrieved from http://en.asaninst.org/contents/ issue-brief-no-39-koreas-public-diplomacy-a-new-initiative-for-the-future/.

Strauß, N., Kruikemeier, S., van der Meulen, H., \& van Noort, G. (2015). Digital diplomacy in GCC countries: Strategic communication of Western embassies on Twitter. Government Information Quarterly, 32(4), 369-379.

The Japan Foundation. (2018). 2016/2017 The Japan foundation annual report. Retrieved from http://www.jpf.go.jp/e/about/result/ar/2016/pdf/index.html.

Yun, S. (2014). Do international students direct experiences with the host country lead to strong attitude-behavior relations? Advancing public diplomacy research and beyond. International Journal of Communication, 8, 787-806.

Xu, W. W., Park, J. Y., Kim, J. Y., \& Park, H. W. (2016). Networked cultural diffusion and creation on YouTube: An analysis of YouTube memes. Journal of Broadcasting \& Electronic Media, 60(1), 104-122.

Xu, W. W., Park, J. Y., \& Park, H. W. (2015). The networked cultural diffusion of Korean Wave. Online Information Review, 39(1), 43-60.

Xu, W. W., Park, J. Y., \& Park, H. W. (2017). Longitudinal dynamics of the cultural diffusion of Kpop on YouTube. Quality \& Quantity, 51(4), 1859-1875.

Zaharna, R. S. (2005). The network paradigm of strategic public diplomacy. Policy Brief, 10(1), 1-4.

Zaharna, R. S., Arsenault, A., \& Fisher, A. (2013). Introduction: The connected mindshift. In R. S. Zaharna, A. Arsenault, \& A. Fisher (Eds.). Relational, networked and collaborative approaches to public diplomacy: The connective mindshift (pp. 15-28). New York: Routledge. 